\title{
Speech Writing and Types of Speeches ${ }^{1}$
}

\author{
Ricky Telg ${ }^{2}$
}

This publication about speech writing and types of speeches is the second of a three-part series about developing effective public speaking skills. This series also covers an introduction to public speaking and public speaking tools.

\section{Introduction}

This publication focuses on structuring the speech and utilizing proper writing techniques. Each speech should be comprised of three major parts: introduction, body, and conclusion. However, before writing the speech, you may want to outline the major points. An outline provides a framework that arranges the major points and supporting materials. Rearrange the major ideas in the speech until you believe the layout will have the greatest impact on your listeners.

\section{Writing the Speech}

After you have analyzed your audience, selected the topic, collected supporting materials, and written an outline, it is time to write the speech.

\section{The Introduction}

The introduction usually states the purpose of the speech. A good introduction serves as an attention getter, previews the topic and main ideas, and establishes your credibility as a speaker (O’Hair, Rubenstein, \& Stewart, 2007). Some good ways to grab attention include using a quotation, telling a story, posing questions, using humor, using startling facts or statistics, providing an illustration or anecdote, or referencing historical or recent events. A preview statement identifies the main points of the speech, helping the audience focus on the key points of the remainder of the presentation.

The audience determines your credibility based on the introduction - they want to know why they should believe what you have to say. Therefore, establishing yourself as a credible speaker in the introduction is imperative, especially for a persuasive speech, so that the audience will want to be persuaded by you. You should include some experience or knowledge that shows why you are credible on the topic.

\section{The Body}

The body is the largest part of the speech, where you provide the audience with the major supporting materials. The main points of the speech are contained in this section. Main points should flow from the speech's goal and thesis statement. It is advisable to limit your content to include between two and five main points, with a maximum of seven main points. Speeches with three main points are common. If you have too many main points, your audience will forget them. Focusing on a few points and providing effective supporting points for each makes your speech more memorable. Supporting points are the supporting materials you have collected to justify your main points. These help to substantiate your thesis.

\section{The Conclusion}

The conclusion wraps up the presentation by providing a summary of what the audience was supposed to have

1. This document is WC116, one of a series of the Department of Agricultural Education and Communication, Florida Cooperative Extension Service, Institute of Food and Agricultural Sciences, University of Florida. Original publication date August 2011.Visit the EDIS website at http://edis.ifas.ufl.edu.

2. Ricky Telg, professor, Department of Agricultural Education and Communication, Florida Cooperative Extension Service, Institute of Food and Agricultural Sciences, University of Florida, Gainesville, FL 32611. 
learned or have been persuaded to do during the presentation. You can signal that the conclusion is approaching by using key phrases, such as "finally," "let me close by saying," "I'd like to stress these three points," and "in conclusion." Because the conclusion is the last opportunity to motivate your listeners, it should end strongly. For a persuasive speech, a strong ending would be a call to action, where you tell the audience members they should do something with the information they have learned.

Many times, you can use a mirrored conclusion example that ties back to or "mirrors" the information you provide in the introduction. For example, if you use statistics as your attention-getting method in the introduction to a speech about recycling on campus, your speech's beginning and ending might sound something like this:

Introduction: "According to the University of Florida's Office of Sustainability, the campus used more than 4 million trash bags in 2006 alone, weighing 163 tons without the trash. Altogether, UF generates over 14,000 tons of trash per year."

Mirrored Conclusion: "Each time you are about to throw a bottle, can, or newspaper in the trash, decide to recycle it instead and help reduce the 14,000 tons of waste we create each year at UF."

\section{Conversational Speech}

You should write the speech like you talk. Follow these writing tips to make your speech as conversational as possible:

- Use short sentences of 20 words or less. You usually do not use long sentences in a conversation. Short sentenceseven sentence fragments-are fine for a speech.

- Avoid complicated sentence structures. Simple sentences that have a subject, verb, and object are perfect for public speaking.

- Use contractions. "Do not" and "cannot" are usually too formal for most speeches. "Don't" and "can't" are fine. Be careful of contractions ending in "-ve" (e.g., "would've," "could've") because they sound like "would of" and "could of."

- Avoid jargon or technical language. Use words that your audience knows.

- Round large numbers. Detailed numbers should be left out.
- Use repetition. The same word or phrase used repeatedly emphasizes a major point.

- Write with visual imagery. Make your listeners "see" what you are saying. Help them visualize the situation you are describing.

\section{Types of Speeches}

Speeches can be divided into the following categories: the informative speech, the persuasive speech, and speeches for special occasions.

\section{Informative Speech}

If the speech's purpose is to define, explain, describe, or demonstrate, it is an informative speech. The goal of an informative speech is to provide information completely and clearly so that the audience understands the message. Examples of informative speeches include describing the life cycle stages of an egg to a chicken, explaining how to operate a camera, or demonstrating how to cook a side dish for a meal. The organization of the speech depends on your specific purpose and varies depending on whether you are defining, explaining, describing, or demonstrating. Informative demonstration speeches lend themselves well to the use of visual aids to show the step-by-step processes with real objects.

\section{Persuasive Speech}

Persuasive speeches are given to reinforce people's beliefs about a topic, to change their beliefs about a topic, or to move them to act. When speaking persuasively, directly state what is good or bad and why you think so near the beginning of the speech. This is your thesis statement that you want to make early on. Since your purpose is to persuade using logic and reasoning, this communicates to listeners that you want to convince them of your point of view. One way to structure a persuasive speech is to use the five-part argument:

1. The introduction attracts the attention of the audience, sets the tone, and describes what the persuasive speech is about. The introduction usually includes the thesis statement-the specific sentence that explains the main point of the argument.

2. The background provides the context and details needed for a listener to understand the situation being described, as well as the problem or opportunity being addressed.

3. Lines of argument make up the body of the speech. Here is where you include all the claims, reasons, and 
supporting evidence you have that help you make your points effectively.

4. Refuting objections means disproving, ruling out, and countering any potential objections before the listeners can think of reasons not to be persuaded.

5. The conclusion is where you present your closing arguments. To be effective, the conclusion should restate your thesis statement and summarize the main points of your argument. If you are advocating a particular solution to a problem or a decision to be made, you should close by asking your listeners to adopt your point of view.

\section{Speeches for Special Occasions}

Speeches for special occasions are prepared for a specific occasion and for a specific purpose dictated by that occasion (O'Hair et al., 2007). Speeches for special occasions can be informative, persuasive, or both, depending on the occasion. Two of the more common types of speeches for special occasions are the speech of introduction and the speech of welcome.

The speech of introduction is a brief speech that provides the main speaker's qualifications. This speech prepares the audience for the main speaker by establishing the speaker's credibility and helps make the speaker feel welcome. To write the speech of introduction, gather biographical information about the speaker. Try to find out one or two pieces of information about the speaker's background or credentials that would establish a relationship with the audience. The speech of introduction is usually one to no more than three minutes in length.

The speech of welcome acknowledges and greets a person or group of people. The speech of welcome expresses pleasure for the presence of the person or group. The purpose is to make the person or group feel welcome and to provide information about the organization you represent. Find out something about the person or group beforehand that you can include in the speech of welcome. The speech of welcome typically lasts between three and five minutes.

\section{Additional Information}

DiSanza, J. R., \& Legge, N. J. (2005). Business and professional communication: Plans, processes, and performance (3rd ed.).Needham Heights, MA: Allyn \& Bacon.

Hamilton, C. (2012). Essentials of public speaking (5th ed.). Belmont, CA: Wadsworth Cengage Learning.
Koch, A. (2007). Speaking with a purpose. Needham Heights, MA: Allyn \& Bacon.

O'Hair, D., Rubenstein, H., \& Stewart, R. (2007). A pocket guide to public speaking (2nd ed.). Boston, MA: Bedford/St. Martin's. 